Volume 1, Nomor 1, Juli 2018

P-ISSN: 2622-2280 | E-ISSN: 2622-4658

https://ejurnal.iiq.ac.id/index.php/alfanar

\title{
TAPESÉRÉ AKORANG MABBASA OGI
}

Tafsir Al-Qur'an Berbahasa Bugis Karya Agh. Abd. Muin Yusuf

\section{Teguh Arafah ${ }^{1}$}

Institut Agama Islam Negeri Palopo

Email:Teguharafah@gmail.com

\begin{abstract}
Many indigenous Muslims compose a book of interpretation with different types of languages and methods used. Then came the mention of "native" interpretation. For example Tarjumân Mustafìd by 'Abd Rauf Singkel using Malay Language, Al-Ibrîs li Ma'rifat at-Tafsîr Al-Qur'an al-'Azîz karya KH Bishri Musthafâ using Javanese Language, Tahrîf Qulûb al-Mu'minîn fî̀ Tafsîr Sentences Sûrat Yâsîn creation of Ahmad Sanusi ibn 'Abd Rahim. In this article, attempt to reveal one of the literary interpretation of the archipelago from Tana Bugis AGH. Abd Muin Yusuf with his creation TapeséréAkorang Mabbasa Ogi with the Indonesian Council of Ulama (MUI) of South Sulawesi. This book is called the book of Tapesere Akorang Mabbasa Ogi. Its Naming as a practical consideration to facilitate the reader to know and remember the book for the society of Bugis easily achieve the purpose of Al-Qur'an, both in the activities of religion and daily life. The book of Tapeséré Akorang Mabbasa Ogi when viewed in term of its presentation belongs to the category of Tahlili Interpretation, but in the description does not use such a performance with interpretations using this method. By analyzing different aspects in detail, especially the linguistic aspect. It is intended to facilitate the reader Interpretation not to be preoccupied with his analyzes.
\end{abstract}

Keywords: Anre gurutta, ${ }^{2}$ Interpretation of the archipelago, Method.

\section{Abstrak}

Banyak orang Muslim pribumi menyusun kitab tafsir dengan berbagai jenis bahasa dan metode yang digunakan. Kemudian muncullah penyebutan tafsir "pribumi". Misalnya, Tarjumân Mustafìd karya 'Abd Rauf Singkel menggunakan bahasa Melayu, Al-Ibrîs li Ma'rifat at-Tafsîr Al-Qur'an al-'Azîz karya KH. Bishri Musthafa menggunakan bahasa Jawa, Tahrîf Qulûb al-Mu'minîn fî̀ Tafsîr Kalimat Sûrat Yâsîn karya Ahmad Sanusi ibn 'Abd Rahim. Pada artikel

1 Dosen Institut Agama Islam Negeri Palopo

2 Anre Gurutta adalah sebuah istilah gelar bagi ulama Sulawesi Selatan, yang semakna dengan gelar kiyai di Jawa, Buya di Minang, Tuan Guru di Banjarmasin dan Nusa Tenggara Barat. Namun, gelar ini ada perbedaan bagi ulama tua dan muda. Untuk ulama tua dipakai istilah Anre Gurutta (disingkat AG), sementara ulama muda dipakai istilah Gurutta (disingkat G). Istilah ini tidak dipakai secara umum kepada seseorang yang dianggap sebagai ulama, tetapi hanya dipakai kepada ulama/ustadz dalam lingkup pesantren itupun hanya dalam bentuk panggilan kepada guru, bukan dalam bentuk penulisan nama gelar. Sekitar pertengahan tahun 90 -an istilah mulai dipakai secara umum, baik yang dalam lingkup pesantren maupun di luar. 
ini berupaya mengungkap salah satu literatur tafsir Nusantara dari tanah Bugis yakni AGH. Abd Muin Yusuf dengan karyanya Tapeséré Akorang Mabbasa Ogi bersama tim Majelis Ulama Indonesia (MUI) Wilayah Sulawesi Selatan. Kitab ini bernama kitab Tapeséré Akorang Mabbasa Ogi. Pemberian nama tersebut sebagai pertimbangan praktis untuk memudahkan para pembaca mengetahui dan mengingat kitab tersebut, sehingga masyarakat Bugis mudah mencapai tujuan Al-Qur'an, baik dalam aktivitas keberagamaannya maupun kehidupan sehariharinya. Kitab Tapeséré Akorang Mabbasa Ogi jika dilihat dari segi penyajiannya termasuk kategori tafsir Tahlili, tetapi dalam uraiannya tidak menggunakan cara kerja metode tahlili, yaitu, dengan menganalisis berbagai aspeknya secara detail, terutama aspek kebahasaan. Hal itu dimaksud untuk memudahkan pembaca tafsirnya sehingga tidak disibukkan dengan analisis-analisisnya.

Kata Kunci: Anre gurutta, Tafsir Nusantara, Metode.

\section{PENDAHULUAN}

ari abad ke abad, karya tafsir berkembang pesat beserta dengan inovasi gaya, bentuk dan metode yang bermacam-macam. Terdapat beberapa tafsir 30 juz dengan pendekatan dan nuansa yang berbeda, tafsir surah tertentu, tema tertentu, tafsir akademik, non-akademik, tafsir yang mengacu dengan metodologi maupun yang bersifat konvensional serta jenis tafsir yang lain. Keragaman tersebut muncul dipengaruhi oleh beberapa faktor diantaranya latar belakang penulis, baik dari sisi keilmuan ataupun sosialnya, masalah yang dihadapi, sasaran tafsir, terobosan baru dan sebagainya.

Proses penafsiran Al-Qur'an juga sudah ada sejak masuknya agama Islam di Nusantara, proses penulisan tafsir diperkirakan mulai muncul sekitar abad ke-16 M. Setidaknya ini dapat dilihat dari naskah Tafsir Surah al-Kahfi [18]: 9. Meski tidak diketahui siapa penulisnya, manuskrip ini diduga dibuat pada masa awal pemerintahan Sultan Iskandar Muda (1607-1636) dan dibawa dari Aceh ke Belanda oleh seorang ahli bahasa Arab dari Belanda, Erpinus (w. 1624) pada awal abad ke-17 M. ${ }^{3}$ Pendapat lain menyatakan aktivitas seputar Al-Qur'an di Indonesia dirintis oleh Abdul Rauf al-Singkili (1615-1693 M) yang menerjemahkan Al-Qur'an ke dalam bahasa melayu pada pertengahan abad ke-17 yang dinamai Tarjumân al-Mustafîd. ${ }^{4} \mathrm{Hal}$ ini menjadi salah satu upaya yang menunjukkan semangat umat Islam di Indonesia dalam mengkaji Al-Qur'an, dengan munculnya terjemahan-terjemahan Al-Qur'an dan tafsirnya ke dalam bahasa lokal (daerah).

Lahirnya literatur tafsir dan terjemahan Al-Qur'an dalam bahasa daerah merupakan respon dan pengaruh dari latar belakang sosio-budaya dan kultur bahasa para mufasir. Hal ini dapat dipahami mengingat tafsir Al-Qur'an merupakan hasil konstruksi intelektual seorang mufassir dalam menjelaskan pesan-pesan wahyu Tuhan yang terkandung di dalam Al-Qur'an sesuai dengan kebutuhan manusia di dalam lingkungan sosial dan budaya dengan kompleksitas nilai-nilai yang melingkupinya. ${ }^{5}$

3 Islah Gusmian, Khazanah Tafsir Indonesia dari Hermeneutika hingga Ideologi, (Jakarta Selatan: Teraju, 2003), h. 41.

4 Musyrifah Sunanto, Sejarah Peradaban Islam Indonesia, (Jakarta: PT Raja Grafindo, 2007), h. 289.

Imam Muhsin, Tafsir Al-Qur'an dan Budaya Lokal: Studi Nilai-Nilai Budaya Jawa dalam Tafsir al-Huda Karya Bakri Syahid, (Jakarta: Badan LITBANG dan DIKLAT Kementerian Agama RI, 2010), h. 6 .

108 I Al-Fanar: Jurnal Ilmu Al-Qur'an dan Tafsir 
Diantara unsur penting yang senantiasa melekat dalam kebudayaan masyarakat adalah bahasa. Hal ini berlaku juga pada penafsiran Al-Qur'an yang dilakukan oleh mufasir yang berasal dari lingkungan budaya tertentu. Makna yang diinginkan mufasir tersebut akan tergambar dari bahasa yang ia gunakan yang disesuaikan dengan budaya yang ada disekitarnya. ${ }^{6}$ Salah satu sistem bahasa yang tidak dapat dipisahkan dari budaya dan realitas masyarakat penggunanya adalah bahasa bugis.

Suku Bugis banyak berdiam di Indonesia Timur ataupun yang berada di daerah Nusantara ini, juga memiliki kebutuhan mendasar terhadap tafsir Al-Qur'an. Suku Bugis merupakan salah satu suku di Indonesia yang dikenal sangat kental menganut dan melaksanakan ajaran-ajaran agama Islam. Dalam hal ini mereka bergantung pada apa yang mereka peroleh dari Al-Qur'an, sehingga tafsir Al-Qur'an memegang peranan penting dalam kehidupan keagamaannya. ${ }^{7}$

Terdapat beberapa karya tafsir yang menggunakan bahasa Bugis sebagai bahasa pengantar, ${ }^{8}$ tapi pada penelitian ini, penulis fokus pada salah satu kitab tafsir lokal, yang

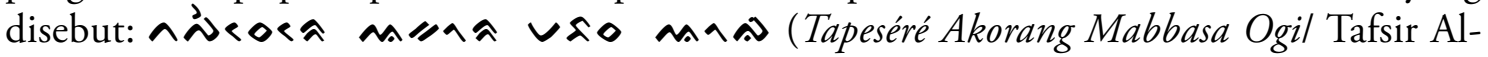
Qur'an Berbahasa Bugis) yang merupakan karya bersama AGH. Abd. Muin Yusuf dan Tim MUI Sul-Sel. ${ }^{?}$

Tulisan ini juga dimaksudkan sebagai upaya untuk mengungkap khazanah tafsir yang ada di bumi Nusantara, khususnya di Sulawesi-Selatan dan mengangkat sekaligus memperkenalkan salah satu karya ulama kharismatik - dari suku Bugis- yang menunjukkan keseriusannya dalam menafsirkan Al-Qur'an. Berangkat dari hal ini, penulis berkeinginan meneliti untuk menemukan Karakteristik Kitab Tapeséré Akorang Mabbasa Ogi karya AGH. Abd. Muin Yusuf.

\section{SEKILAS TENTAG KITAB TAPESÉRÉ AKORANG MABBASA OGI Biografi AGH. Abdul Muin Yusuf}

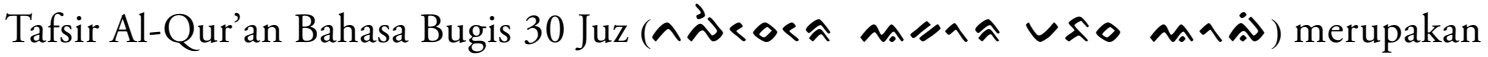
ide dan prakarsa Andre gurutta yang kala itu menjabat sebagai ketua Majelis Ulama Indonesia (MUI) (selama dua periode 1985-1990 dan 1990-1995). Kala itu ia membentuk satu tim penulis dengan beberapa ulama di Sulawei-Selatan dalam penyusunan kitab tafsir tersebut. Namun, dalam perjalannya tim ini tidak berjalan efektif sehingga dengan komitmen yang dimilikinya Andre gurutta meneruskan dan merampungkan penulisannya, sehingga dikemudian hari kitab tafsir ini dikenal pula dengan Tafsir al-Mu’inn.

6 Nasr Hamid Abu Zaid, Mafhûm an-Nâs Dirâsah fî 'Ulûm Al-Qur'an, terj. Khairon Nahdliyyin, Tekstualitas Al-Qur'an: Kritik Terhadap Ulumul Qur'an, (Yogyakarta: Lkis. 2002), h. 19.

M. Rafi Yunus Martan, “Membidik Universalitas, Mengusung Lokalitas: Tafsir Al-Qur'an Bahasa Bugis Karya AG.H. Daud Ismail”, Jurnal Studi Al-Qur'an, Vol. 1, (2006), h. 521-522.

8 Hal demikian dapat dilihat sebagai berikut : M⿻ : (Ajusu Amma na Bettuangngié Sibawa Basa Ugi yang ditulis oleh AGH. Nuh Daeng Manompo al-Boni,

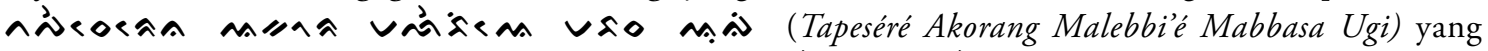

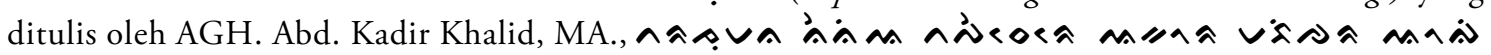
(Tarjumanna Nannia Tapeséré Akorang Mabbicara Ogi) yang ditulis oleh AGH. Daud Ismail Soppeng,

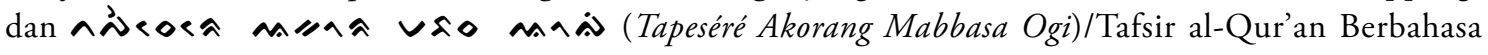
Bugis) yang merupakan karya bersama AGH. Abd. Muin Yusuf dan tim MUI Sul-Sel.

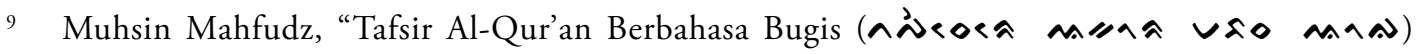
Karya AGH. Abd. Muin Yusuf.” Al-Fikr, Vol. 15, (Juni 2011), h. 35 
Berikut dipaparkan biografi singkat Andre gurutta yang disebutkan dalam muqaddimahnya, ${ }^{10}$ yaitu ${ }^{11}$ : Andre gurutta memiliki nama Abdul Muin Yusuf. Beliau dilahirkan di Rappang, Kabupaten Sidrap, 21 Mei 1920 dari pasangan Muhammad Yusuf dari Bulu Patila Sengkang dan Sitti Khadijah dari Rappang Sidrap. Ketika berusia 10 tahun, Andre gurutta memperoleh pendidikan dasar di Inlandsche School (Sekolah Dasar zaman Belanda) pada pagi hari dan belajar di Madrasah Ainur Rafie pimpinan Syekh Ali Mathar pada sore hari dan selesai pada tahun 1933. Kemudian Andre gurutta melanjutkan studi ke Madrasah Arabiyah Islamiyah (MAI) Sengkang pimpinan AGH. Muhammad As'ad dan selesai pada tahun 1973, melanjutkan studi ke Normal Islam Majene, Sulawesi Barat, kemudian pindah ke Pinrang mengikuti kepindahan Normal Islam (berubah nama menjadi Mu'allimat Ulya) ke Kab. Pinrang (1993-1942).

Selanjutnya pada tahun 1942 Andre gurutta diangkat menjadi Qâdhi (Bugis: Kali) Sidendreng, menggantikan mertuanya Syekh Ahmad Jamaluddin sebagai patner Addatuang (gelar kebangsawanan raja Sidenreng) dalam urusan keagamaan. Lima tahun kemudian di tahun 1947, Andre gurutta melepaskan jabatannya sebagai Kali, dan berkesempatan menunaikan haji ke Tanah Suci sekaligus berniat mukim (tinggal) untuk menuntut ilmu di Darul Falah Mekkah, dengan mengambil jurusan perbandingan mazhab dan kembali ke Tanah Air pada tahun 1949 setelah merampungkan pendidikannya selama dua tahun. ${ }^{12}$

Andre gurutta berkontribusi dalam memajukan pendidikan di Sulawesi-Selatan sebagai tempat penyaluran ilmunya, antara lain Madrasah Ibtida'iyyah Nashrul Haq (1942-1945), Madrasah Tarbiyah Islamiyah (MTI) (1949-1954). Pada awal Orde Baru mendirikan Yayasan Pendidikan Islam (YMPI), dan Sekolah Menengah Islam (SMI) yang kemudian berubah menjadi Sekolah Guru Islam Atas (SGIA), kemudian berubah lagi menjadi Pendidikan Guru Agama (PGA), selanjutnya menjadi Sekolah Persiapan IAIN (SP-IAIN). Dan terakhir mendirikan pesantren Al-Urwatul Wutsqâ (1974) di Kelurahan Benteng, Kecamatan Baranti. Di lembaga inilah Andre gurutta mengabdi sampai akhir hayatnya. Andregurutta juga menjadi salah satu pencetus berdirinya lembaga pendidikan Islam Dâr ad-Da'wah wa al-Irsyâd (DDI, 1946). ${ }^{13}$

Karya-karya yang pernah ditorehkannya antara lain: Fiqh Muqâranah berbahasa Bugis (1953), al-Khutbah al-Mimbâriyyah berbahasa Bugis (1944), Tafsir Al-Qur'an bahasa Bugis $30 \mathrm{Juz}$, yang diterbitkan MUI Sulawesi-Selatan sebanyak 11 jilid (disusun pada tahun 1988-1996). ${ }^{14}$

\section{Karakteristik Kitab Tapeséré Akorang Mabbasa Ogi}

\section{Ciri-ciri Umum}

Kitab Tapeséré Akorang Mabbasa Ogi ini mulai ditulis pada tahun 1988 dan selesai ditulis pada hari kamis tanggal 20 Oktober 1996 bertepatan dengan tanggal 1 jumadil Akhir

10 Majelis Ulama Indonesia Sulawesi-Selatan, Tapeséré Akorang Mabbasa Ogi (Tafsir Al-Qur'an Berbahasa Bugis), Jilid 1, h. 4.

11 Meskipun pada akhirnya AGH. Muin Yusuf lah yang merampungkan kitab tafsir ini 30 juz

12 Muhammad Ruslan dan Waspada Santing, ed., Ulama Sulawesi Selatan: Biografi Pendidikan dan Dakwah, (Makassar: Komisi Informasi dan Komunikasi MUI Sulawesi Selatan, 2007), h. 97-99.

13 Muhammad Harun dan St. Khadijah, "AG. H. Abdul Muin Yusuf; Ulama Pejuang dari Sidenreng," dalam buku Ulama Sulawesi Selatan: Biografi Pendidikan dan Dakwah, h. 99-102.

14 Muhsin Mahfudz, “Tafsir Al-Qur'an Berbahasa Bugis”, h. 37. 
$1416 \mathrm{H}$ di Makassar. ${ }^{15}$ Nama kitab tafsir ini dapat dilihat pada sampul depan kitab yang berwarna biru gelap. Bagian paling atas ditulis dalam bahasa Bugis yaitu ヘさくくくくえ

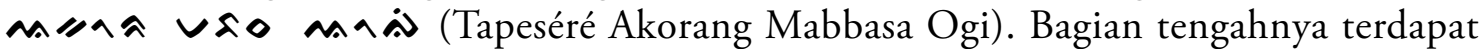
bundaran yang bertuliskan Tafsîr Al-Qur'an al-Karîm dalam bahasa Arab, kemudian menyebutkan jilid dan lembaga MUI Sul-Sel dalam bahasa Bugis. Pemberian nama tersebut kemungkinan sebagai pertimbangan praktis untuk memudahkan para pembacanya mengetahui dan mengingat nama tafsirnya, yang mana sasaran pembacanya adalah masyarakat Bugis, sebagaimana disebutkan dalam muqaddimahnya, Andre gurutta berkata:

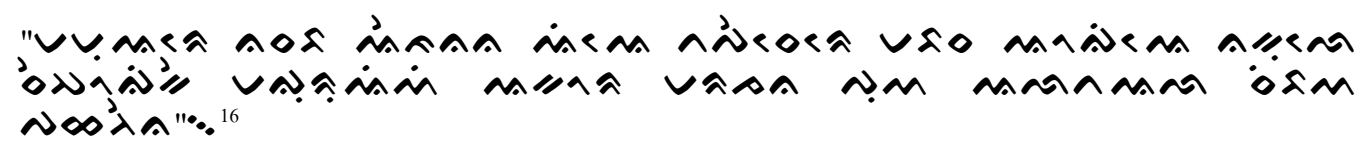

Transliterasinya:

Mammuaréq nasaba engkana iyaé tapeséré mabbasa ogié nakullé sempugikeng magguruiwi akorang marajanna puang Allahta'ala sibawa pahangengna (Semoga dengan adanya tafsir Al-Qur'an berbahasa Bugis ini, saudara kita orang Bugis dapat mempelajari Al-Qur'an kitab besar-Nya Allah ta'ala serta memahaminya).

Pada bagian pendahuluan, Andre gurutta mengungkapkan beberapa hal yaitu latar belakang penyusunannya, kerjasama dalam penulisannya yaitu MUI Sul-Sel, referensi atau kitab rujukan tafsirnya, metodologi yang dipakai, dan para penulisnya. Secara fisik, seperti yang disebutkan diawal pendahuluan tafsir ini, Andre gurutta merencanakan merancang dari awal untuk mencetaknya dalam 10 jilid dan dalam setiap jilidnya terdiri dari 3 juz. ${ }^{17}$ Dalam kenyataannya, Tafsir berbahasa Bugis terdiri dari 11 Jilid dan setiap jilidnya tidak selalu terdiri dari 3 juz, kecuali pada tiga jilid pertama. Menurut Mursalim, hal ini terjadi karena tafsir ini diselesaikan oleh Andre gurutta dan tidak tersusunnya sebagaimana rencana awal adalah pertimbangan bahwa apabila telah memenuhi syarat penerbitan maka diterbitkanlah. ${ }^{18}$

\section{Latar Belakang dan Tujuan Penulisan}

Salah satu yang memotivasi Andre gurutta dalam penulisan kitab ini yaitu: pertama, Kesadaran dirinya sebagai seorang ulama untuk menjelaskan dan menyebarkan makna yang terkandung dalam Al-Qur'an yang berbahasa Arab kepada muslim Bugis yang menggunakan bahasa Bugis sebagai bahasa pengantar dalam kehidupan kesehariannya. Dalam bagian pendahuluan Andre gurutta menyatakan:

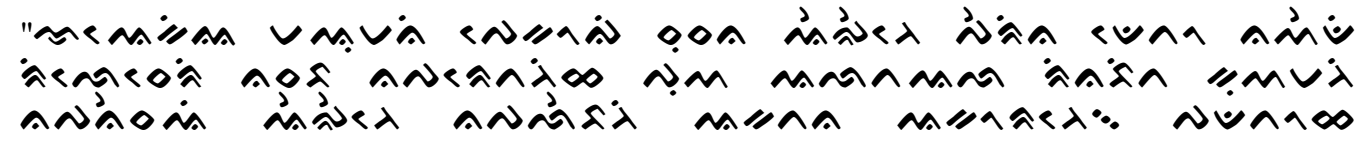

15 Mursalim, "Corak Pemikiran Tafsir Ulama Bugis (Suatu Kajian Kitab Tafsir Al-Qur'an Karim Karya Majelis Ulama Indonesia (MUI) Sulawesi Selatan”, Disertasi, h. 86. Tidak diterbitkan. Mengenai penerbitan, tidak disebutkan tahun berapa dan di mana kitab ini diterbitkan, hanya didapat informasi dari dua pengantar yang diberikan Gubernur Sulawesi-Selatan yaitu Ahmad Amiruddin dan Ka. Kanwil Sul-Sel Abdurrahman K, yang tertulis pada tahun 1988. Hal tersebut mengindikasikan bahwa kitab ini ditulis sekitar tahun itu.

16 Majelis Ulama Indonesia Sulawesi-Selatan, Tapeséré Akorang Mabbasa Ogi,Jilid 1, h. 1.

17 Majelis Ulama Indonesia Sulawesi-Selatan, Tapeséré Akorang Mabbasa Ogi, Jilid 1, h. 3.

18 Mursalim, “Corak Pemikiran Tafsir Ulama Bugis (Suatu Kajian Kitab Tafsir Al-Qur'an Karim Karya Majelis Ulama Indonesia (MUI) Sulawesi Selatan”, Disertasi, h. 88. Tidak diterbitkan 


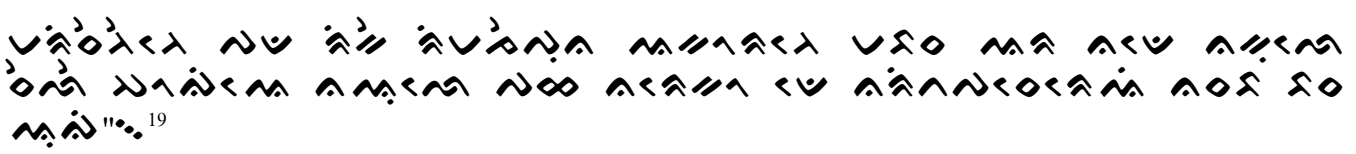

Transliterasinya:

Naiyyakiya maumani pekkogi sussana endrengnge perrina deqto nawedding rilésséri nasana naparentangengngi ha puang Allah ta'ala ri nabitta kuammengngi napannessai endrengngé napallebbangngi akkatana akorangngé. Padatoha marissengengngé pada rikke rimajeppuna akorangnge mabbasa araq nade nakkulle selleng ogie naullé pahang narékko dé naritapasséréngngi nasaba basa ogi (Bagaimanapun susah dan sulitnya (Tafsir Bahasa Bugis), (kita) tidak boleh menghindarinya karena itu merupakan perintah Allah Swt. kepada Nabi untuk menjelaskan dan menyebarkan kandungan Al-Qur'an yang berbahasa Arab itu, sementara masyarakat muslim Bugis tidak dapat memahaminya jika tidak ditafsirkan ke dalam bahasa Bugis).

Kedua, Meringankan sekaligus melepaskan beban tanggung jawab sebagai ulama Bugis dari tuntutan agama yang bersifat fardhu kifâyah. Andre gurutta menyatakan:

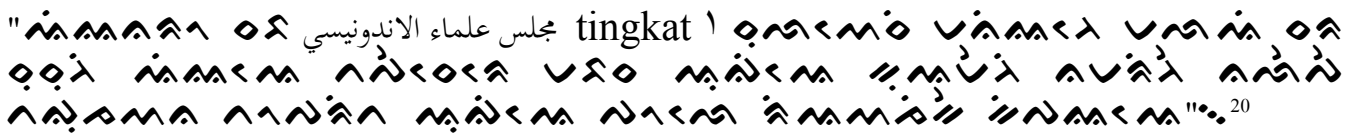

Transliterasinya:

Iyanaro saba majlis 'ulamầ al-Indunîsî tingkat satu sulawesi maniyangnge Malawi sara susungngi iyae tapeséré mabbasa ugié kuammengngi namaringeng naleppe tanggungjawàna topanrita ugié pole riawajikeng kipayaé (Itulah sebabanya Majelis Ulama Indonesia tingkat satu Sulawesi-Selatan mengambil tindakan menyusun tafsir berbahasa Bugis, agar dapat meringankan (sekaligus) melepaskan (beban) tanggung jawab ulama Bugis dari kewajiban fardhu kifâyah).

Adapun tujuan penulisan tafsir dalam bahasa Bugis ini antara lain: 1) ^ッe

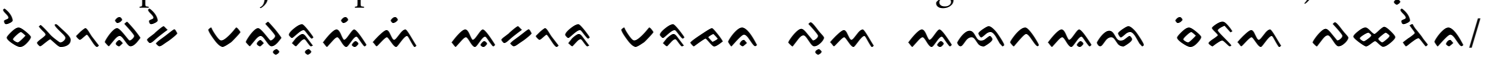
Nakkulle seppugikeng maggurui akorang marajanna puang Allah ta'ala sibawa pahangenna (agar orang Bugis dapat mempelajari Al-Qur'an (kitab) besar-Nya Allah ta'ala serta

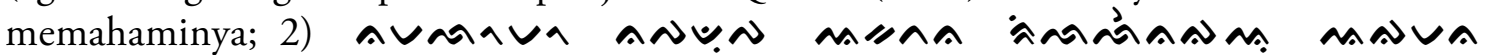

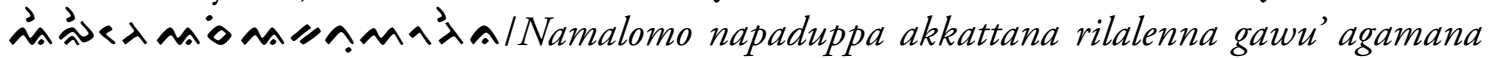
endrengngé assiatuw ongenna (agar mudah mencapai tujuannya, baik dalam aktivitas

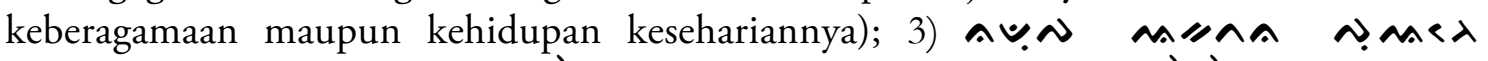

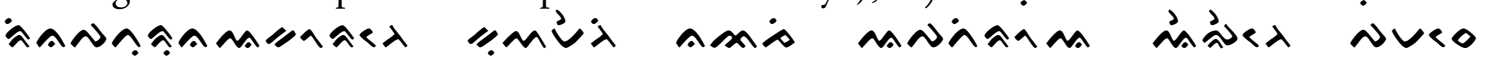

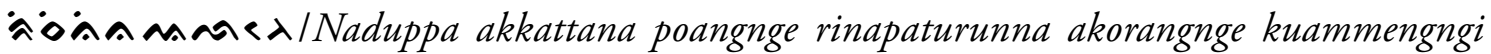
nancaji apatiroang endrengngé pammasé risininna alangngé (menemukan tujuan Allah Swt. menurunkan Al-Qur'an, yaitu dapat menjadi petunjuk maupun rahmat bagi seluruh alam). ${ }^{21}$

\section{Sumber Kitab Tapeséré Akorang Mabbasa Ogi}

Sumber yang bisa kita lihat dalam kitab Tapesere Akorang Mabbasa Ogi yang pertama disebut tafsîr bi al-ma'tsûr (bi an-naql), dan kedua disebut tafsîr bi al-Máqûl (bi al-

\footnotetext{
19 Majelis Ulama Indonesia Sulawesi-Selatan, Tapeséré Akorang Mabbasa Ogi,Jilid 1, h. 2.

20 Majelis Ulama Indonesia Sulawesi-Selatan, Tapeséré Akorang Mabbasa Ogi, Jilid 1, h. 2.

21 Majelis Ulama Indonesia Sulawesi-Selatan, Tapeséré Akorang Mabbasa Ogi, Jilid 1, h. 1
} 
Ra'yi). ${ }^{22}$ Ada juga yang menambahkan dengan tafsîr bi al-isyârî yakni penakwilan berdasarkan isyarat-isyarat tersembunyi yang berasal dari suluk seorang sufi. ${ }^{23}$

\section{a. Tafsîr bi al-ma'tsûr}

Tafsîr bi al-ma'tsûr ialah tafsir yang berdasarkan pada Al-Qur'an atau riwayat yang shahih sesuai urutan yang telah disebutkan dalam syarat-syarat mufasir. ${ }^{24}$ Dalam konteks Tapeséré Akorang Mabbasa Ogi, dapat ditemukan beberapa contoh tafsîr bi al-ma'tsûr. Hal ini tidak dapat dipungkiri terutama jika melihat buku rujukannya, salah satunya adalah kitab Tafsîr Al-Qur'an al-Azhîm karya Abû al-Fidâ' Ismâ'îl ibn Katsîr yang dikenal sebagai kitab tafsir riwâyah. Berikut dipaparkan beberapa contohnya:

Pertama, Menafsirkan Al-Qur'an dengan Al-Qur'an, sebagaimana ketika menafsirkan kisah Nabi Adam as. QS. al-Baqarah [2]: 37,

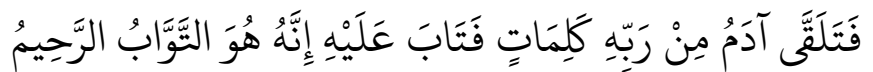

kata "kalimât" dalam ayat tersebut diartikan doa sebagaimana disebutkan dalam QS al-'A'râf [7]: 23. Berikut kutipannya:

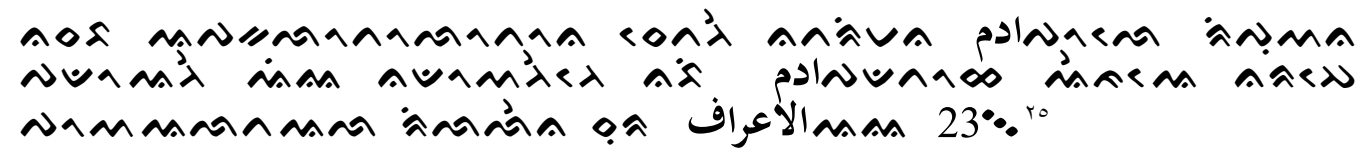

Transliterasinya:

Nasaba appakalontoq-lontoqna sétangngé natarimana Adam polé ripuwanna paddoangeng iya naddowangengngé nabi Adam dapatoha engkaé narampé poang-Allahtaala rilalenna sura al-'A'raf aya 23. (Karena godaan setan, Adam menerima sebuah doa dari Tuhannya yang dipakai oleh Nabi Adam, seperti yang difirmankan Allah ta'ala dalam surah al-'A'râf ayat 23)

Kedua, Menafsirkan Al-Qur'an dengan Hadis, sebagaimana ketika menafsirkan makna "subhânah" dalam QS. al-Baqarah [2]: 116, Andre gurutta mengutip beberapa hadis Nabi perihal pensucian Allah. Salah satunya yaitu:

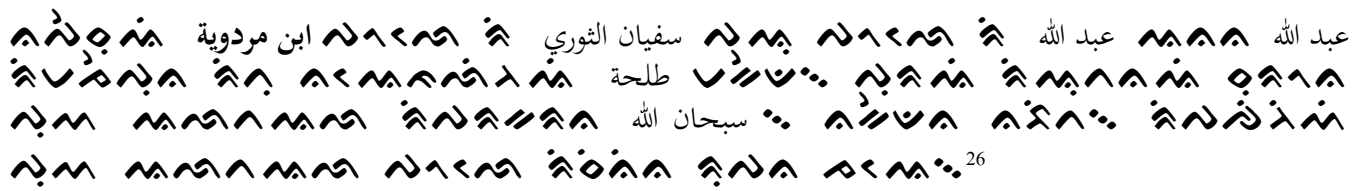

Transliterasinya:

Napessu'i Ibn Mardawiyyah pole ri Sufyân al-Saurî pau pole ri Abdullah anaqna 'Abdullah rimajeppuna naéngkalingai Talhâh makkeda: purai riuwakkutanai surona puang-Allah-ta'ala ripakarana "subhanallah". Makedanna nabitta: ripaccingiwi puangAllah-ta'ala pole risininna rupanna jâ é (Dikeluarkan oleh Ibn Mardawiyyah dari Sufyân ats-Tsaurî dari 'Abdullah anaknya 'Abdullah, telah mendengar dari Tâlhâh

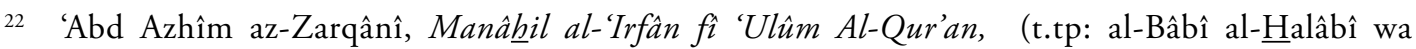
Shurakah, t.th.), Jilid 2 h. 141.

23 Muhammad Husain adz-Dzahabî, at-Tafsîr wa al-Mufassirîn, (Kairo: Maktabah Wahbah, t.th.), Juz 2, h. 261.

24 Mannâ' Khalîl al-Qaththân, Studi Ilmu-Ilmu Qur'an, terj. Mudzakir, (Jakarta: Pustaka Litera Antar Nusa, 2011), h. 482-483

25 Majelis Ulama Indonesia Sulawesi-Selatan, Tapeséré Akorang Mabbasa Ogi, Jilid 1, h. 64.

26 Majelis Ulama Indonesia Sulawesi-Selatan, Tapeséré Akorang Mabbasa Ogi, Jilid 1, h. 170 
berkata: aku telah bertanya kepada utusannya Allah mengenai perihal mensucikan Allah. Nabi Bersabda: yakni mensucikan Allah-ta’ala dari segala hal yang buruk).

\section{b. Tafsîr bi ar-Ra'yî}

Tafsîr bi ar-ra'ŷे adalah penafsiran Al-Qur'an yang memberikan keleluasaan terhadap penggunaan subjektivitas penafsir dengan menggunakan akal untuk memahami AlQur'an. ${ }^{27}$ Dari segi bentuk, cenderung dikatakan bahwa kitab Tapeséré Akorang Mabbasa Ogi adalah at-tafsîr bi ar-ra'yî. Jika dibandingkan antara riwayat dengan kutipan pendapat ulama tafsir maupun ulama lainnya yang dilibatkan oleh Andre gurutta dalam 60 ayat Surah al-Baqarah, ternyata Andre gurutta lebih banyak menggunakan pendapat ulama ditambah pendapat sendiri dibandingkan riwayat, yakni 7 riwayat banding 21 pendapat ulama, selebihnya merupakan pendapat Gurutta sendiri. ${ }^{28}$

Salah satu contoh pendapat Andre gurutta dapat dilihat saat menafsirkan QS. al-Mầûn [107]: 2, tentang ciri orang yang mendustakan agamanya. Andre gurutta mengartikan kata

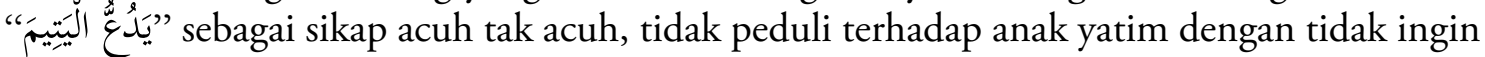
memeliharanya, dan dengan tega tidak memberikan apapun padanya.

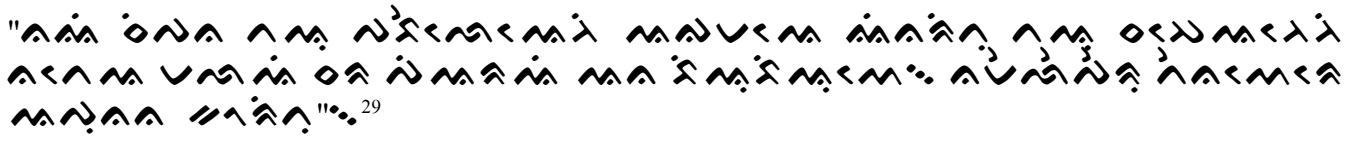

Transliterasinya:

Nayi sipana tau pabbellééngngi agamaé yinaritu tau sampeangengngi natea malai sara piarawi ana biu-biue. Namelle’perrû tennawéréng appunnanna koritu. (Adapun sifat orang yang mendustakan agama yaitu orang yang menolak serta tidak mau peduli untuk memelihara anak yatim. Dan tega tidak memberikan apapun padanya).

c. Tafsîr bi al-isyârî

Tafsir sufi atau tafsir isyârî secara etimologis berasal dari akar kata asyâra-yusyîruisyâratan yang berarti memberi isyarat atau petunjuk. Dasar penafsirannya adalah bahwa Al-Qur'an mencakup apa yang zahir dan batin, makna zahir dari Al-Qur'an adalah teks ayatnya. Sedangkan makna batinnya adalah makna isyarat dibalik makna zhâhir. Tafsir isyârî oleh para ahli tafsir bisa diterima jika memenuhi syarat sebagai berikut: pertama, tidak bertentangan dengan lahir ayat; kedua, mempunyai dasar rujukan dari ajaran agama yang sekaligus berfungsi sebagai penguatnya; ketiga, tidak bertentangan dengan ajaran agama dan akal; keempat, tidak menganggap bahwa penafsiran model itu yang paling benar sesuai yang dikehendaki Allah. ${ }^{30}$

Dapat disimpulkan, tafsir sufi nazharî adalah penafsiran Al-Qur'an yang tidak memperhatikan aspek dan kaidah kebahasaan. Sedangkan tafsir sufi isyârî adalah pentakwilan ayat-ayat Al-Qur'an yang berbeda dengan makna zahirnya sesuai dengan petunjuk khusus yang diterima para tokoh sufisme, tetapi diantara kedua makna tersebut dapat dikompromikan. ${ }^{31}$

27 Gusmian, KhazanahTafsir Indonesia, (Yogyakarta: LKiS, 2013), h. 217-218

28 Muhsin Mahfudz, “Tafsir Al-Qur'an Berbahasa Bugis”, h. 41.

29 Majelis Ulama Indonesia Sulawesi-Selatan, Tapeséré Akorang Mabbasa Ogi, Jilid 11, h. 815

30 Muhammad ㅂusain adz-Dzahabî, at-Tafsîr wa al-Mufassirûn, Juz I h. 377.

31 Muh. Said, "Metodologi Penafsiran Sufistik: Perspektif al-Gazali", Diskursus Islam, Vol. 2 (Juni 2014), h. 149.

114 | Al-Fanar: Jurnal Ilmu Al-Qur'an dan Tafsir 


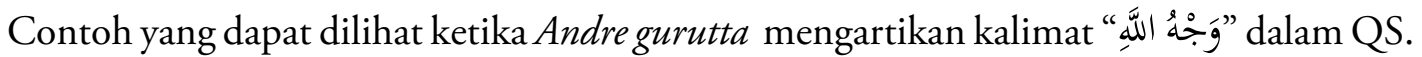
al-Baqarah [115:[2, dengan riona fuang Allah táalâ (ridha-Nya Allah Swt.). Ini menandakan Andre gurutta tidak menerjemahkannya dengan makna harfiah, melainkan menakwilkannya dengan makna majâzî, yang merupakan esensi tafsir isyârî. Berikut kutipannya:

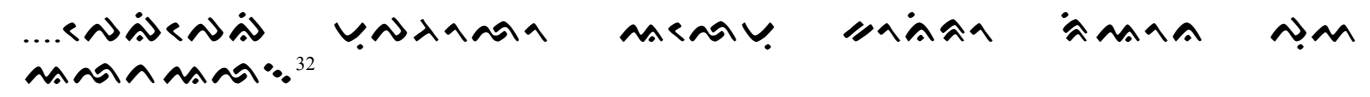

Transliterasinya:

Pégi-pégi muangolong alému koniro riona puang Allah tảala (Dimanapun kau hadapkan wajahmu disitulah ridha-Nya Allah Swt.)

Lahan penafsiran kelompok sufi salah satunya adalah huruf muqaththa'ah. Adapun Andre gurutta dalam menyikapi ayat-ayat tersebut tidak memberikan penafsiran kecuali hanya mengikuti pendapat pendahulunya dalam menafsirkan, yaitu bahwa Allah saja yang lebih mengetahui maksudnya. Andre gurutta merujuk pendapat ulama misalnya Ibn Katsîr dan Imam ar-Râzi. Menurutnya, penempatan satu ayat dengan huruf hijaiyyah di beberapa surah Al-Qur'an adalah untuk menunjukkan kemukjizatan Al-Qur'an dan membuktikan bahwa manusia tidak mampu menyusun seperti susunan Al-Qur'an. ${ }^{33}$

\section{Metode Tafsir Kitab Tapeséré Akorang Mabbasa Ogi}

Al-Farmâwî memetakan metodologi penafsiran Al-Qur'an menjadi empat bagian pokok, yaitu: Tahlîlî, Muqâran, Ijmâli, dan Maudhû̀i. ${ }^{34}$ Dalam konteks kitab Tapeséré Akorang Mabbasa Ogi jika dilihat dari segi penyajiannya termasuk dalam kategori tafsir Tahlîlî, ${ }^{35}$ dengan sistematika penyajian runtut ${ }^{36}$ dengan mengikuti urutan mushaf Usmani, yaitu penafsirannya dimulai dari surah al-Fâtihah sampai akhir surah an-Nâs. Meskipun dikategorikan sebagai tafsir yang menggunakan metode Tahlîlî, tetapi dalam uraianuraiannya tidak menggunakan cara kerja seperti dengan tafsir-tafsir yang menggunakan metode ini, dengan menganalisis berbagai aspeknya secara mendetail, terutama aspek kebahasaan. ${ }^{37} \mathrm{Hal}$ itu dimaksudkan untuk memudahkan para pembaca tafsirnya untuk

32 Majelis Ulama Indonesia Sulawesi-Selatan, Tapeséré Akorang Mabbasa Ogi, Jilid 1, h. 162.

33 Majelis Ulama Indonesia Sulawesi-Selatan, Tapeséré Akorang Mabbasa Ogi, Jilid 11, h. 24-25.

34 Hal tersebut merupakan konsekuensi logis dari adanya keinginan umat Islam untuk selalu mendialogkan antara Al-Qur'an sebagai teks wahyu yang terbatas dengan perkembangan persoalan sosial kemasyarakatan yang dihadapi oleh manusia sebagai konteks yang kompleks dan tak terbatas. Lihat alFarmâwî, al-Bidâyah fî at-Tafsîr al-Maudhî̀î: Dirâsah Manhajiyyah Maudhûìyyah, h. 23.

35 Tahlîlî berasal dari bahasa Arab hallala-yuhallalu-tahlîl yang bermakna membuka sesuatu atau tidak menyimpang sesuatu darinya, atau bisa juga berarti membebaskan, mengurai, menganalisis. Lihat Ahmad bin Fâris bin Zakariyâ, Mu'jam Maqâyis al-Lughah, (Beirut: Dâr al-Fikr, 1979 M/1399 H), Juz 2, h. 20. Lihat juga Muhammad bin Mukrim bin Ali Abu al-Fadhil Jamâluddin bin Mandzûr, Lisân al'Arab̂̀, (Beirut: Dâr ash-Shâdir, 1414 H), Juz 11, h. 163. Lihat juga M. Quraish Shihab, dkk. Sejarah dan 'Ulum Al-Qur'an, h. 172.

36 Sistematika penyajian runtut adalah model sistematika penyajian penulisan tafsir yang rangkaian penyajiannya mengacu pada; (1) urutan surah yang ada dalam model mushaf standar, atau (2) mengacu pada urutan turunnya wahyu. Kitab Tapeséré Akorang Mabbasa Ogi memakai metode yang pertama. Islah Gusmian, Khazanah Tafsir Indonesia: dari Hermeneutika hingga Ideologi, h. 123.

37 Tafsir metode tahlîlî menyajikan penjelasan rinci terhadap kosakata dan lafadz, munâsabah,

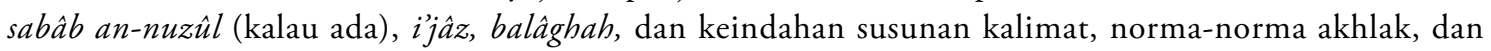
lain sebagainya. Lihat M. Quraish Shihab, Kaidah Tafsir: Syarat, ketentuan dan Aturan yang Patut Anda Ketahui Dalam Memahami Ayat-Ayat Al-Qur'an (Tangerang: Lentera Hati, 2013), h. 378. 
tidak disibukkan dengan berbagai analisisnya, sehingga mereka dapat lebih cepat memahami kandungan ayat-ayatnya.

Jika dilihat dari segi uraian-uraian yang ditampilkan, aspek analisisnya menggunakan metode Ijmâli, ${ }^{38}$ meskipun dari segi runtutan pembahasan ayatnya ia termasuk dalam kategori Tahlîlî. Setelah diterjemahkan setiap kelompok ayatnya kedalam bahasa Bugis yang memiliki padanan yang mendekati makna harfiah Arabnya. Selanjutnya tafsir ini menjelaskan kandungan ayat-ayatnya tanpa menguraikan dengan detail tentang problem kebahasaan. Dalam menjelaskan kandungan ayat, Asbâb an-Nuzûl digunakan sebagai salah satu alat analisisnya.

Gaya bahasa penulisan yang ditampilkan tafsir ini termasuk dalam gaya penulisan populer, yakni gaya bahasa penulisan karya tafsir yang menempatkan bahasa sebagai medium komunikasi dengan karakter kebersahajaan. Kata maupun kalimat yang digunakan, dipilih yang sederhana dan mudah. ${ }^{39}$

Dengan demikian, dapat disimpulkan bahwa dari segi bentuk, kitabTapesere Akorang Mabbasa Ogi dikategorikan sebagai tafsîr bi ar-ra'yi, dari segi metode ia termasuk Tafsir Tahlîlî dengan sistematika penyajian runtut, dari aspek analisisnya menggunakan metode Ijmâli, dari segi gaya bahasa penulisan ia menggunakan gaya penulisan populer, dan dari segi corak, tidak didominasi oleh kecenderungan tertentu.

\section{PENUTUP}

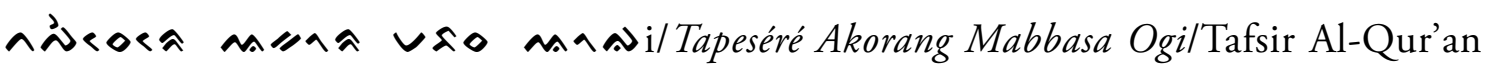
Berbahasa Bugis yang merupakan karya bersama AGH. Abd. Muin Yusuf dan tim MUI Sul-Sel 1985- 1995 menjadi salah satu karya ulama dari tanah Bugis yang menambah daftar literatur tafsir Nusantara. Namun, dalam perjalannya tim ini tidak berjalan efektif, Andregurutta meneruskan dan merampungkan penulisannya, sehingga dikemudian hari kitab tafsir ini dikenal pula dengan Tafsir al-Mu'în.

Motivasi Andre gurutta dalam penulisan kitab ini merupakan kesadaran dirinya sebagai seorang ulama untuk menjelaskan dan menyebarkan makna yang terkandung dalam AlQur'an yang berbahasa Arab kepada muslim Bugis yang menggunakan bahasa Bugis sebagai bahasa pengantar dalam kehidupan kesehariannya dan agar mencapai tujuannya, baik dalam aktivitas keberagaman maupun kehidupan kesehariannya.

Jika dilihat dari segi uraian-uraian yang ditampilkan, dapat disimpulkan bahwa dari

38 Metode ijmali yaitu menafsirkan Al-Qur'an dengan cara singkat dan global, tanpa uraian panjang lebar. Cara kerja metode ialah mengulas setiap ayat Al-Qur'an dengan sangat sederhana, tanpa ada upaya untuk memberikan improvisasi makna dengan pengkayaan dan wawasan lain, sehingga pembahasan yang dilakukan hanya menekankan pada aspek pemahaman yang ringkas tapi padat, tidak bertele-tele, dan bersifat global. Makna yang diungkapkan biasanya diletakkan di dalam rangkaian ayat-ayat atau menurut pola-pola yang diakui oleh jumhur ulama, dan mudah dipahami oleh semua orang. Abd. Muin Salim, dkk., Metodologi Penelitian Tafsir Maudhû̀î, (Yogyakarta: Pustaka al-Zikra, 2011), h. 42, dan Mardan, Al-Qur'an Sebuah Pengantar, (Ciputat: Madzhab Ciputat, 2010), h. 258.

39 Islah Gusmian memetakan gaya penulisan tafsir dengan empat bentuk: 1) Gaya penulisan kolom yaitu gaya penulisan tafsir dengan memakai kalimat yang pendek, lugas, dan tegas. 2) Gaya bahasa penulisan reportase yaitu dengan menggunakan kalimat yang sederhana, elegan, komunikatif, dan lebih menekankan pada hal yang bersifat pelaporan, dan bersifat human intrest. 3) Gaya penulisan ilmiah yaitu suatu gaya bahasa penulisan yang dalam proses komunikasinya terasa formal dan kering. Model seperti ini kebanyakan suatu karya tafsir akademik. 4) Gaya bahasa popular, seperti uraian di atas. Islah Gusmian, Khazanah Tafsir Indonesia: dari Hermeneutika hingga Ideologi, h. 180. 
segi bentuk, kitab Tapeséré Akorang Mabbasa Ogi dikategorikan sebagai tafsîr bi ar-Rajyi, dari segi metode ia termasuk Tafsir Tahlîlî dengan sistematika penyajian runtut, dari aspek analisisnya menggunakan metode Ijmâli, dari segi gaya bahasa penulisan ia menggunakan gaya penulisan populer, dan dari segi corak, tidak didominasi oleh kecenderungan tertentu.

\section{DAFTAR PUSTAKA}

Al-Almầi, Zhahir bin Awad, Dirâsât fî at-Tafsîr al-Maudlû̀i li Al-Qur'an al-Karîm, Riyadh: t.p., $1404 \mathrm{H}$.

Al-Farmâwî, al-Bidâyah fî at-Tafsîr al-Maudlû̀̂̀: Dirâsah Manhajiyyah Maudlû̀iyyah, t.tp: t.p, t.th.

Gusmian, Islah, Khazanah Tafsir Indonesia dari Hermeneutika hingga Ideologi, Jakarta Selatan: Teraju, 2003. KhazanahTafsir Indonesia, Yogyakarta: LKiS, 2013.

Ibn Fâris, Mưjam Maqâyîs al-Lughah, Beirut: Dâr al-Fikr, 1979 M/1399 H.

Ibn Manzhûr Muhammad bin Mukrim bin Ali Abu al-Fadhil Jamâluddin, Lisân al-'Arabî,, Beirut: Dâr ash-Shâdir, $1414 \mathrm{H}$.

Mahfudz, Muhsin, "Tafsir Al-Qur'an Berbahasa Bugis (tpEeser akor mbs aogi) Karya AGH. Abd. Muin Yusuf." Al-Fikr, Vol. 15, (Juni 2011)

Mardan, Al-Qur'an Sebuah Pengantar, Ciputat: Madzhab Ciputat, 2010.

Martan, M. Rafi Yunus, "Membidik Universalitas, Mengusung Lokalitas: Tafsir Al-Qur'an Bahasa Bugis Karya AG.H. Daud Ismail”, Studi Al-Qur'an, Vol. 1, (2006).

Muhsin, Imam, Tafsir Al-Qur'an dan Budaya Lokal: Studi Nilai-Nilai Budaya Jawa dalam Tafsir al-Huda Karya Bakri Syahid, Jakarta: Badan Litbang dan Diklat Kementerian Agama RI, 2010.

Mursalim, "Corak Pemikiran Tafsir Ulama Bugis (Suatu Kajian Kitab Tafsir Al-Qur'an Karim Karya Majelis Ulama Indonesia (MUI) Sulawesi Selatan”, Disertasi,

Al-Qaththân, Mannâ’ Khalil, Studi Ilmu-Ilmu Qur'an, terj. Mudzakir, Jakarta: Pustaka Litera Antar Nusa, 2011

Ruslan, Muhammad dan Waspada Santing, ed., Ulama Sulawesi Selatan: Biografi Pendidikan dan Dakwah, Makassar: Komisi Informasi dan Komunikasi MUI Sulawesi Selatan, 2007.

Said, Muh., "Metodologi Penafsiran Sufistik: Perspektif al-Gazali”, Diskursus Islam, Vol. 2 (Juni 2014

Salim, Abd. Muin, dkk., Metodologi Penelitian Tafsir Maudhu'i, Yogyakarta: Pustaka al-Zikra, 2011

Shihab, M. Quraish, Kaidah Tafsir: Syarat, ketentuan dan Aturan yang Patut Anda Ketahui Dalam Memahami Ayat-Ayat Al-Qur'an, Tangerang: Lentera Hati, 2013.

Sunanto, Musyrifah, Sejarah Peradaban Islam Indonesia, Jakarta: PT Raja Grafindo, 2007.

Tim Majelis Ulama Indonesia Sulawesi-Selatan, Tapeséré Akorang Mabbasa Ogi (Tafsir AlQur'an Berbahasa Bugis), t.tp: t.p., t.th.

Zaid, Nasr Hamid Abu, Mafhûm an-Nâs Dirâsahfî̀ 'UlûmAl-Qur'an, terj. Khairon Nahdliyyin, Tekstualitas Al-Qur'an: Kritik Terhadap Ulumul Qur'an, Yogyakarta: Lkis. 2002 
Tafsir Al-Qur'an Berbahasa Bugis Karya Agh. Abd. Muin Yusuf

Adz-Dzahabî, Muhammad Husain, at-Tafsîr wa al-Mufasirûn, Kairo: Maktabah Wahbah, t.th.

Az-Zarqânî, Abd al-'Azhîm, Manâhil al-'Irfân fì 'Ulûm Al-Qur'an, t.tp: al-Bâbî al-Halâbî wa Shurakah, t.th. 